\title{
Brain-Reactive Lymphocytotoxic Antibodies in the Serum of Patients with Systemic Lupus Erythematosus
}

\author{
Harry G. Bluestenn and Nathan J. Zvaifler \\ From the Department of Medicine, University of California Medical Center, \\ San Diego, California 92103
}

\begin{abstract}
A B S T R A C T Homogenized tissue from the frontal cortex of normal human brains obtained at postmortem examination was used to absorb lymphocytotoxic antibody from the serum of six patients with systemic lupus erythematosus (SLE). Four absorptions of all of the SLE sera with equal volumes of homogenized brain tissue at $4^{\circ} \mathrm{C}$ depleted their cytotoxic capacity more than $90 \%$. Three of the six sera, however, retained some lymphocytotoxicity despite extensive brain absorption. Absorbed lymphocytotoxic antibodies were eluted from brain tissue absorbents at $37^{\circ} \mathrm{C}$. Cytotoxicity of the brain eluates was blocked by antibodies to human IgM ( $\mu$-chain specific) but not anti-IgG. The unabsorbed SLE sera, brain-absorbed sera, and brain eluates were equally cytotoxic to $T$ (thymus-derived) and B (bone marrow-derived) cells fractionated from normal human peripheral blood lymphocytes. Thus, the lymphocytotoxic antibodies in SLE serum exhibit no preference for circulating human $\mathrm{T}$ cells.

An analysis of the clinical records of 40 patients with SLE whose serum cytotoxic capacity had been determined revealed that circulating lymphocytotoxicity is greater in sera of patients with central nervous system (CNS) manifestations than in other SLE patients. This observation suggests a possible role for brain-reactive lymphocytotoxic antibodies in the development of CNS disease in SLE.
\end{abstract}

\section{INTRODUCTION}

Serum from most patients with systemic lupus erythematosus (SLE) ${ }^{1}$ contain immunoglobulins whose anti-

Received for publication 15 July 1975 and in revised form 16 October 1975.

1 Abbreviations used in this paper: B, bone marrow derived; $\mathrm{CC}_{50}, \log _{2}$ of the reciprocal of the greatest serum dilution killing $50 \%$ of normal human peripheral blood lymphocytes; CNS, central nervous system; FCS, fetal calf serum; HBSS, Hank's balanced salt solution; NHS, normal human serum; PBL, peripheral blood lymphocytes; SLE, systemic lupus erythematosus; $T$, thymus derived. body activity is directed at heterologous and autologous lymphocytes. Several methods have been used to detect these antibodies including immunofluorescence $(1,2)$, lymphocytotoxicity, (3-5), and suppression of in vitro lymphocyte function (6-9). Of these antilymphocyte factors, complement-dependent IgM lymphocytotoxic antibodies have been most thoroughly investigated. The antigenic determinants on the lymphocyte surface with which the cytotoxic antibody reacts have not yet been defined. A comparison of the cytotoxicity of SLE serum to lymphocytes from healthy individuals and patients with chronic lymphocytic leukemia led Lies et al. (10) to conclude that the antibodies were relatively $\mathrm{T}$-(thymus-derived) cell specific. More recently, however, Winfield et al. (11) have shown that SLE sera are cytotoxic to both $\mathrm{T}$ - and B-(bone marrow-derived) cells purified from the peripheral blood of normal individuals. Thus, it seems possible that SLE sera contain varying amounts of antibody directed at $\mathrm{T}$ - or B-cell determinants and that the observed specificity of any individual serum depends on the relative proportion of those antibody populations.

Since, in mice, it has been shown that there are shared antigenic determinants between $T$ cells and brain tissue (12), we have attempted to separate anti-Tfrom anti-B-cell antibodies by absorption of SLE serum with human brain tissue. We found that human brain removed most, but not all, of the lymphocytotoxic activity. A portion of the absorbed antibody could be eluted from the brain. Brain absorption, however, did not separate the antibodies according to $T$ - or $B$-cell specificity. The cytotoxic antibodies in the unabsorbed SLE sera, in the brain-absorbed sera, and in the eluates from the brain absorbents reacted equally against $B$ and $T$ lymphocytes. A comparison of serum cytotoxic capacity with specific systemic manifestations of SLE reveals that central nervous system (CNS) disease is associated with increased lymphocytotoxicity. This observation suggests a possible pathogenic role for the circulating brain-reactive antibodies. 


\section{METHODS}

Clinical material. Sera were obtained from 40 randomly chosen patients with SLE, all of whom fulfilled the preliminary diagnostic criteria of the American Rheumatism Association (13). Sera from six patients were studied in detail. Four of the six were selected for study because they were strongly cytotoxic, each having a 50\% lymphocytotoxicity titer of $1: 64$ or greater $\left(C_{50}\right.$ greater than 6$)$. The other two patients' sera were relatively weakly cytotoxic, each with $50 \%$ cytotoxicity titers of $1: 2$. A pool of normal human sera (NHS) comprised of a mixture of unequal amounts of serum from 12 healthy adult donors was used as a control serum source. The sera were stored at $-20^{\circ} \mathrm{C}$ without preservatives. Before use, all sera were heated at $56^{\circ} \mathrm{C}$ for $45 \mathrm{~min}$.

The clinical records of each of the 40 patients were reviewed retrospectively to identify systemic manifestations of SLE. Renal disease was considered to be present if a kidney biopsy showed glomerulonephritis, or if there were erythrocytes and red cell casts in the urine sediment, or if the 24-h urinary protein excretion was greater than $1 \mathrm{~g}$, or if the creatinine clearance was less than $60 \mathrm{~cm}^{3} / \mathrm{min}$. The criteria for CNS involvement included seizure disorder, organic brain syndrome, aseptic meningitis, steroid-responsive psychosis, or other psychiatric disturbances requiring hospitalization. Patients were considered to have serositis if there was objective evidence for pleuritis, pericarditis, or peritonitis. Hemolytic anemia or thrombocytopenia were the criteria for hematologic disease.

Cytotoxicity assay. The cytotoxicity in the SLE sera was determined by the microdroplet dye exclusion cytotoxicity assay as described by Terasaki et al. (3) with little modification. Target lymphocytes were obtained from the peripheral blood of healthy adult volunteer donors by differential density centrifugation as previously described (14). The lymphocyte-rich population from $10 \mathrm{ml}$ of blood was washed two times by $190 \mathrm{~g}$ centrifugation at $4^{\circ} \mathrm{C}$ in 10 $\mathrm{cm}^{3}$ of Hank's balanced salt solution supplemented with $10 \%$ fetal calf serum (HBSS-FCS). The washed lymphocytes were then suspended in HBSS-FCS at a density of $10^{8}$ cells $/ \mathrm{ml}$. $1 \mu \mathrm{l}$ of that suspension was combined with $1 \mu 1$ of each serial twofold dilution of test serum in the well of a microtiter tray (Falcon Plastics, Division of Bioquest, Oxnard, Calif.). Each serum dilution was tested in triplicate. The trays were incubated for $30 \mathrm{~min}$ at $4^{\circ} \mathrm{C}$, after which $5 \mu$ l of rabbit serum that had been prescreened for lack of cytotoxicity to human lymphocytes was added as a source of complement and the incubation continued for an additional $3 \mathrm{~h}$ at $15^{\circ} \mathrm{C} .3 \mu \mathrm{l}$ of $5 \%$ aqueous eosin was then added followed within a few minutes by the addition of 8 $\mu 1$ of $40 \%$ formaldehyde adjusted to $\mathrm{pH} 7.0 .100$ cells were examined in each well, and the number of cells stained with eosin enumerated. The mean percentage of dead cells in the triplicate assays was expressed as percent cytotoxicity. The $50 \%$ cytotoxicity titer $\left(C_{50}\right)$, that is, the $\log _{2}$ of the reciprocal of the greatest serum dilution producing $50 \%$ cytotoxicity, provided a measure of the relative cytotoxic capacity of each serum.

Absorptions. Tissue from the frontal cortex of human brains known to be free of pathology were obtained at postmortem examination within $24 \mathrm{~h}$ after death. After removal of the meninges and surface blood vessels, the tissue was finely diced with a scalpel and then homogenized by hand in a ground glass TenBroeck homogenizer. The homogenate from each gram of tissue was suspended in $5 \mathrm{ml}$ of HBSS and washed four times by $2,000 \mathrm{~g}$ centrifugation at $4^{\circ} \mathrm{C}$ for $15 \mathrm{~min}$. For each absorption the packed homogenate was resuspended in an equal volume of serum at $4^{\circ} \mathrm{C}$ for $1 \mathrm{~h}$. The absorbed serum supernate was removed after centrifugation of the suspension at 2,000 g for $15 \mathrm{~min}$ at $4^{\circ} \mathrm{C}$. Absorptions with a liver homogenate prepared in the same fashion as the brain homogenate and absorptions with human erythrocytes were also done at a 1:1 ratio of the volume of packed cells to serum volume.

Elutions. After removal of the serum supernate, the pelleted brain homogenate used for the first serum absorption was washed four times by centrifugation in 5 vol of $0.01 \mathrm{M}$ phosphate buffer, pH 7.4 in $0.15 \mathrm{M} \mathrm{NaCl}$ (phosphate-buffered saline) maintained at $4^{\circ} \mathrm{C}$. The pelleted homogenate was then resuspended in an equal volume of phosphatebuffered saline and incubated at $37^{\circ} \mathrm{C}$ for $45 \mathrm{~min}$. After centrifugation the supernatant brain eluate was removed.

Lymphocyte fractionation. Normal human peripheral blood lymphocytes (PBL) were fractionated into $T$ and $B$ cell-rich populations by fractionation on columns of nylon wool (Leuko-Pak, Travenol Laboratories, Deerfield, Ill.). $\mathrm{T}$ cells were obtained as previously described (15). Usually $50 \times 10^{6} \mathrm{PBL}$ in $1 \mathrm{ml}$ were applied to columns containing $600 \mathrm{mg}$ of nylon wool. After incubation at $37^{\circ} \mathrm{C}$ for 45 min, the nonadherent cells were removed by the dropwise application of $25 \mathrm{ml}$ of medium. About 20-30 $\times 10^{6}$ lymphocytes were recovered in the eluate. There were greater than $85 \%$ erythrocyte-rosetting cells and less than $5 \%$ surface immunoglobulin-bearing cells (detectable by direct immunofluorescence) in that $\mathrm{T}$ cell-rich population. After washing the column with an additional $100 \mathrm{ml}$ of medium, the nylon wool was compressed to the bottom of the column and the wash discarded. Fresh medium $(8 \mathrm{ml})$ was added to the columns and the nylon wool then agitated up and down through the medium about five times. The medium was drained with recompression of the wool, another $8 \mathrm{ml}$ of medium was added, and the agitation procedure repeated. When combined, the two 8-ml effluents contained $2-4 \times 10^{\circ}$ lymphocytes, of which more than $80 \%$ had surface immunoglobulin and less than $5 \%$ were erythrocyte rosetting. This $\mathrm{B}$-cell population and the previously obtained $\mathrm{T}$ cells were centrifuged at $190 \mathrm{~g}$ for $10 \mathrm{~min}$ at $4^{\circ} \mathrm{C}$ and resuspended at a concentration of $10^{6}$ cells $/ \mathrm{ml}$ for use in the cytotoxicity assay.

\section{RESULTS}

Absorption with brain tissue effectively diminished the lymphocytotoxic activity of serum from all six patients with SLE. The results obtained after absorption of three of the more potently lymphocytotoxic sera are shown in Fig. 1. Absorption of a fourth strongly cytotoxic serum, $\mathrm{CH}$ (not shown in the figure), produced results essentially identical to serum AF. Before absorption, sera $\mathrm{AF}, \mathrm{JH}$, and $\mathrm{CH}$ each had a $50 \%$ lymphocytotoxicity titer of $1: 128$ and serum $\mathrm{AO}$ had a titer of 1:64. Each of the initial brain absorptions lowered the percent cytotoxicity obtained. After three absorptions all four sera produced $50 \%$ lymphocytotoxicity at a $1: 4$ dilution. Thus, three absorptions with brain tissue remove more than $90 \%$ of the lymphocytotoxic activity from these sera. The cytotoxicity of sera $\mathrm{AO}, \mathrm{AF}$, and $\mathrm{CH}$ was not further diminished by additional absorptions. A fourth absorption of serum $\mathrm{JH}$, however, lead to further depletion of its cytotoxicity, reducing it to below $30 \%$. Brain absorption completely removed lym- 


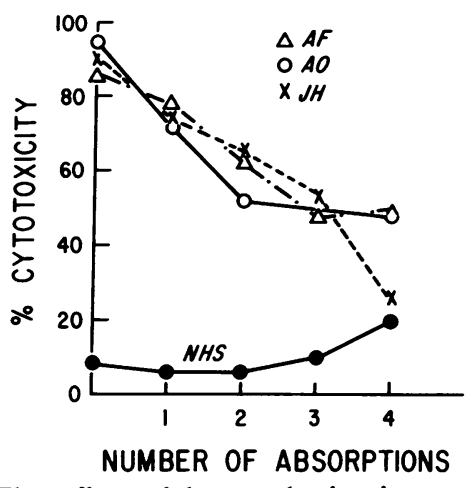

FIGURE 1 The effect of human brain tissue absorption on the lymphocytotoxicity in SLE sera. The residual percent cytotoxicity in a $1: 2$ dilution of SLE sera AF, AO, and JH after absorption with equal volumes of homogenized brain is presented as a function of the number of brain absorptions. The cytotoxicity in a similarly absorbed NHS is presented for comparison.

phocytotoxic activity from two weakly cytotoxic sera. Sera LF and AH, both killing $50 \%$ of normal human lymphocytes at a $1: 2$ dilution, exhibited less than $10 \%$ cytotoxicity after two brain absorptions. There is little change in the lymphocytotoxic activity of the pooled NHS after three brain absorptions, but after the fourth absorption there is a consistent increase to greater than $20 \%$ cytotoxicity (Fig. 1). The percent cytotoxicities obtained after four brain absorptions of serum $\mathrm{JH}$ and the NHS pool are not significantly different. Absorption with brain tissue, then, removes most of the lymphocytotoxicity from all of the lupus sera tested, but some of the sera contain lymphocytotoxic activity that is not brain reactive.

The brain antigens with which the lymphocytotoxic antibodies combine are not present on rodent brain. A comparison of the effects of four absorptions of serum $\mathrm{JH}$ with human or mouse brain homogenates is presented in Table I. Absorption with human brain tissue removes nearly all of the cytotoxic activity while identical absorptions with mouse brain have virtually no effect. Rat brain has also been tested and it, too, is unable to remove significant amounts of lymphocytotoxicity from SLE sera. Thus, the reactivity of lymphocytotoxic antibody with human brain is not the result of nonspecific binding to mammalian cerebral tissue.

The ability of other nonlymphoid tissues of human origin to deplete lymphocytotoxic activity from SLE sera has been examined. The effects of absorptions of serum $\mathrm{JH}$ with erythrocytes, liver, and brain tissue are presented in Fig. 2. Multiple absorptions with equal volumes of packed erythrocytes had no effect on the cytotoxic capacity. Three other sera were similarly absorbed and they, too, were completely unaffected. In each case the erythrocytes used for absorption were
TABLE I

Comparison of Human and Mouse Brain Tissue as Absorbents of Lymphocytotoxicity from SLE Serum*

\begin{tabular}{lccc}
\hline & \multicolumn{3}{c}{ Cytotoxicity } \\
\cline { 2 - 4 } Serum dilution & Unabsorbed & Human brain & Mouse brain \\
\hline & & $\%$ & \\
$1: 2$ & $91 \pm 2$ & $27 \pm 3$ & $90 \pm 4$ \\
$1: 8$ & $86 \pm 3$ & $13 \pm 1$ & $85 \pm 8$ \\
$1: 32$ & $70 \pm 8$ & $16 \pm 6$ & $72 \pm 6$ \\
$1: 128$ & $48 \pm 6$ & $13 \pm 3$ & $27 \pm 1$ \\
\hline
\end{tabular}

* Serum JH was tested at the dilutions indicated either unabsorbed or absorbed four times with homogenized human or mouse brain tissue as described in the Methods.

$\ddagger$ The data are expressed as the mean percent cytotoxicity $\pm \mathrm{SE}$ obtained using lymphocytes from four normal donors.

from the same individual providing the lymphocytes serving as targets in the cytotoxicity assay. Two absorptions of serum $\mathrm{JH}$ with liver tissue homogenate (obtained from the same individual providing the brain tissue) also had no effect on the cytotoxic capacity. After three absorptions with liver, however, there was a modest fall in the cytotoxic titer, comparable to that obtained after only one absorption with human brain. Absorption of serum AF with liver and brain from a different individual produced qualitatively similar re-

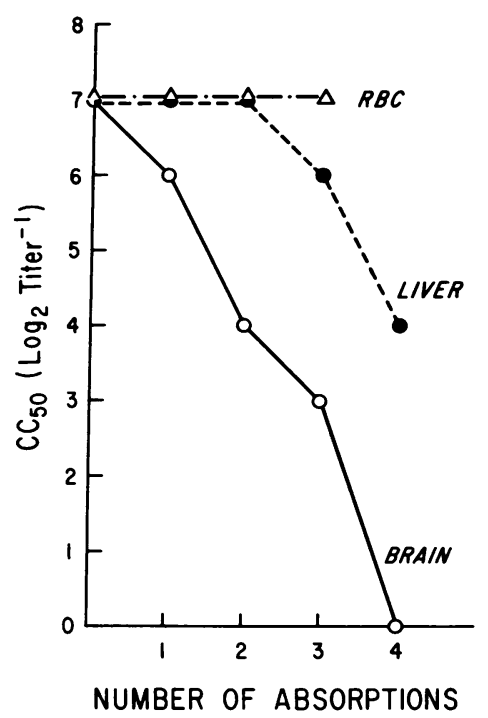

FIGURE 2 A comparison of the effectiveness of human brain, liver, and erythrocytes as absorbents of lymphocytotoxic antibodies from SLE serum. The residual cytotoxic capacity $\left(\mathrm{CC}_{50}\right)$ of serum $\mathrm{JH}$ is presented as a function of the number of absorptions with equal volumes of homogenized brain, homogenized liver, or packed erythrocytes $(\mathrm{RBC})$. 
sults but the liver absorptions were somewhat less effective. Serum AF had a preabsorption $\mathrm{CC}_{50}$ of 7 (50\% lymphocytotoxicity titer of $1: 128$ ). This was reduced to a $\mathrm{CC}_{50}$ of six after four absorptions with liver compared to a $\mathrm{CC}_{50}$ of two after four brain absorptions. Among the human tissues studied, therefore, the lymphocytotoxic antibody is most reactive with brain.

Lymphocytotoxic activity is recoverable from the brain tissue absorbents by elution at $37^{\circ} \mathrm{C}$. The eluates from brain tissue used to absorb SLE sera with high lymphocytotoxic capacity (sera $\mathrm{AF}, \mathrm{AO}$, and $\mathrm{JH}$ ) are themselves highly cytotoxic (Table II). In contrast, the eluates from brain tissue used to absorb NHS are not significantly cytotoxic. Further, there is minimal lymphocytotoxic activity in the eluates from brain tissue used to absorb the weakly cytotoxic serum from LF, a patient with SLE. It appears, therefore, that the amount of lymphocytotoxicity in the brain eluate is proportional to the cytotoxic capacity of the serum from which it was derived.

To define the character of the lymphocytotoxic factor in the brain eluates, we examined the effects of treating the eluates with rabbit antisera to human immunoglobulins. Eluate AO, when mixed with an equal volume of normal rabbit serum, produces a mean cytotoxicity of $74 \%$ (Table III). Mixing that eluate with rabbit serum containing antibodies specific for human IgG (anti- $\boldsymbol{\gamma}$-chain) does not significantly alter the cytotoxicity. The lymphocytotoxic activity is completely eliminated, however, by the addition of antihuman IgM ( $\mu$-chain specific). The rabbit sera themselves are not cytotoxic to the lymphocytes as shown in the control experiments using eluates from brain tissue used to absorb NHS. Elimination of the lymphocytotoxicity of

TABLE II

Lymphocytotoxicity in $37^{\circ} \mathrm{C}$ Eluates from Brain Tissue Used to Absorb SLE Sera

\begin{tabular}{lcc}
\hline $\begin{array}{l}\text { Serum } \\
\text { source* }\end{array}$ & $\begin{array}{c}\text { Serum } \\
\text { CC } 50 \ddagger\end{array}$ & $\begin{array}{c}\text { Eluate } \\
\text { cytotoxicity } 8\end{array}$ \\
\hline & & $\%$ \\
AF & 7 & $90 \pm 2.5$ \\
AO & 6 & $80 \pm 4.2$ \\
JH & 7 & $82 \pm 3.3$ \\
LF & 1 & $25 \pm 8.7$ \\
NHS & 0 & $15 \pm 3.3$
\end{tabular}

* NHS $=$ pooled NHS. Other initials represent individual patients with SLE.

$\ddagger$ The mean $50 \%$ cytotoxicity titer $\left(\mathrm{CC}_{50}\right)$ of the individual sera before brain absorption.

$\S$ The percent cytotoxicity produced by the brain eluate is expressed as the mean $\pm \mathrm{SE}$ obtained using lymphocytes from four normal donors.
TABLE III

Inhibition of the Cytotoxicity of $37^{\circ} \mathrm{C}$ Brain Eluates by Rabbit Antisera to Human Immunoglobulins*

\begin{tabular}{|c|c|c|}
\hline Eluate & Antiserum $\ddagger$ & Cytotoxicity§ \\
\hline & & $\%$ \\
\hline \multirow[t]{3}{*}{ AO } & NRS & 74 \\
\hline & Anti-IgG & 62 \\
\hline & Anti-IgM & 6 \\
\hline \multirow[t]{3}{*}{ NHS } & NRS & 14 \\
\hline & Anti-IgG & 4 \\
\hline & Anti-IgM & 6 \\
\hline
\end{tabular}

* The eluates from homogenized human brain tissue used to absorb SLE serum AO and a serum from a normal healthy individual (NHS) were mixed with an equal amount of a $1: 4$ dilution of the indicated rabbit antisera before testing in the cytotoxicity assay.

$\ddagger$ All of these rabbit sera were heated at $56^{\circ} \mathrm{C}$ for $45 \mathrm{~min}$ before use. The anti-IgG contained $3.9 \mathrm{mg} / \mathrm{ml}$ and the antiIgM $1.8 \mathrm{mg} / \mathrm{ml}$ antibody nitrogen.

$\S$ The data are expressed as the mean percent cytotoxicity obtained in two experiments each using lymphocytes from a different normal donor as the target cells.

the SLE eluate by anti-IgM is not the result of coating the target lymphocytes and protecting them from antibody-mediated lymphocytotoxicity, since $(a)$ target lymphocytes preincubated at $4^{\circ} \mathrm{C}$ in anti-IgM sera and then washed free of nonadherent antibody are unaltered in their susceptibility to the cytotoxic activity of the eluates and $(b)$ addition of the anti-IgM serum to a heterologous rabbit antihuman lymphocyte serum does not alter its cytotoxic activity against human lymphocytes. Thus, IgM antibody appears to be responsible for the lymphocytotoxic activity in the brain eluates.

The specificity of the lymphocytotoxic antibodies for antigenic determinants unique to human $T$ or $B$ cells has been examined by testing the unabsorbed SLE sera, the brain absorbed sera, and the brain eluates for cytotoxic activity against $T$ and $B$ cell-enriched populations prepared by fractionation of normal human PBL. The $B$ cells are somewhat more fragile than the $T$ cells (Table IV). There is $16 \%$ cell death of the $B$ cells in the presence of NHS but only $2 \%$ cytotoxicity of $\mathrm{T}$ cells. Serum JH unabsorbed, at $1: 4$ and $1: 128$ dilutions, is cytotoxic to both $T$ and $B$ cells to the same degree. Brain-absorbed serum $\mathrm{JH}$ has little residual cytotoxicity, but after brain absorption, AF retains lymphocytotoxic antibody which is equally effective against $T$ and $B$ cells. Brain eluates $\mathrm{JH}$ and $\mathrm{AF}$, when tested undiluted, are strongly cytotoxic to all normal lymphocytes. The B cells are somewhat more susceptible than the $T$ cells to the cytotoxicity of $1: 16$ dilutions of both eluates. Thus, the brain-reactive and the nonbrain- 
reactive lymphocytotoxic antibodies, as well as the cytotoxic antibodies in unabsorbed SLE sera, are directed at antigenic determinants present on $\mathrm{B}$ cells and $\mathrm{T}$ cells.

The brain reactivity of circulating lymphocytotoxic antibodies suggests that they might play a role in the CNS manifestation of SLE. Therefore, we retrospectively reviewed the clinical records of the 40 SLE patients in whom we had determined a $50 \%$ cytotoxicity titer. In 15 there was a well-documented neuropsychiatric disorder. 10 had objective evidence of organic CNS dysfunction, 2 developed steroid-responsive acute psychosis during lupus crises, and 3 had severe personality disorders requiring psychiatric hospitalization in concert with worsening laboratory parameters of SLE. The cytotoxic capacity of the serum from the 15 SLE patients with, and the 25 patients without, CNS disease are compared (Table V). The mean $\mathrm{CC}_{50}$ for the group with neuropsychiatric disturbance, 4.5 (a mean $50 \%$ lymphocytotoxicity titer between $1: 16$ and $1: 32$ ), is significantly higher than the mean for the remaining 25 patients, $2.6(P<0.02)$. The mean $\mathrm{CC}_{50}$ of the 18 patients with active lupus nephritis is slightly higher than in those without active renal disease, but

TABLE IV

$T$ - and B-Cell Specificity of Lymphocytotoxic Antibodies in SLE Sera, Brain Absorbed Sera, and Brain Eluates

\begin{tabular}{|c|c|c|c|c|}
\hline \multirow[b]{2}{*}{ Antibody source* } & \multirow[b]{2}{*}{ Dilution $¥$} & \multicolumn{3}{|c|}{ Cytotoxicity $\S$} \\
\hline & & PBL & $\mathbf{T}$ & B \\
\hline & & \multicolumn{3}{|c|}{$\%$} \\
\hline NHS & $1: 2$ & 6 & 2 & 16 \\
\hline Absorbed & $1: 2$ & 7 & 4 & 16 \\
\hline Eluate & $\mathbf{N}$ & 6 & - & - \\
\hline \multicolumn{5}{|l|}{$\mathrm{JH}$} \\
\hline \multirow[t]{2}{*}{ Serum } & $1: 4$ & 92 & 92 & 96 \\
\hline & $1: 128$ & 56 & 44 & 62 \\
\hline Absorbed & $1: 2$ & 22 & 8 & 16 \\
\hline Eluate & $\begin{array}{l}N \\
1: 16\end{array}$ & $\begin{array}{l}90 \\
32\end{array}$ & $\begin{array}{l}80 \\
16\end{array}$ & $\begin{array}{l}84 \\
56\end{array}$ \\
\hline \multicolumn{5}{|l|}{$\mathrm{AF}$} \\
\hline \multirow[t]{2}{*}{ Absorbed } & $1: 4$ & 56 & 76 & 78 \\
\hline & $1: 64$ & 10 & 10 & 12 \\
\hline \multirow[t]{2}{*}{ Eluate } & $\mathbf{N}$ & 88 & 82 & 94 \\
\hline & $1: 16$ & 40 & 16 & 44 \\
\hline
\end{tabular}

* NHS, pooled NHS; Absorbed, serum indicated absorbed four times with human brain homogenate. Eluate, the $37^{\circ} \mathrm{C}$ eluate from the first brain tissue used to absorb the indicated serum. $\ddagger$ The antibody source was diluted as indicated in HBSS before addition to the cytotoxicity assay.

$\$$ The data are expressed as the mean percent cytotoxicity observed using cells from two normal donors. Cytotoxicity was determined using $T, B$, and PBL populations from the same individual. - , not tested.
TABLE V

Comparison of Serum Lymphocytotoxic Capacity with Specific Systemic Manifestations of SLE

\begin{tabular}{lccc}
\hline & & \multicolumn{2}{c}{$\mathrm{CC}_{\text {so }}$} \\
\cline { 3 - 4 } \multicolumn{1}{c}{ System* } & $\begin{array}{c}\text { Number } \\
\text { involved }\end{array}$ & Involved & Uninvolved \\
\hline CNS & 15 & $4.5 \pm 0.8$ & $2.6 \pm 0.4 \S$ \\
Renal & 18 & $3.8 \pm 0.7$ & $2.9 \pm 0.5$ \\
Serosal & 20 & $2.7 \pm 0.5$ & $3.9 \pm 0.6$ \\
Skin & 10 & $3.1 \pm 0.9$ & $3.3 \pm 0.5$ \\
Hematologic & 15 & $4.5 \pm 0.7$ & $2.5 \pm 0.58$ \\
\hline
\end{tabular}

* Determination of system involvement was made by a review of the clinical records of 40 patients with SLE as described in methods.

$\ddagger$ The data are expressed as the mean $50 \%$ cytotoxicity titer $\left(\mathrm{CC}_{50}\right) \pm \mathrm{SE}$.

\& Difference between involved and uninvolved statistically significant $P<0.02$. All other comparisons $P>0.2$. Students $t$ test was used with the $P$ value based on two-tail analysis.

the difference is not statistically significant $(P>0.2)$. If that same comparison is limited to the patients who did not have CNS disease, there was no difference between the mean $\mathrm{CC}_{50}$ of those with or without renal disease. Neither the presence of active skin disease nor serositis (pleuritis, pericarditis, or peritonitis) are associated with increased cytotoxic capacity. SLE patients with hematologic abnormalities (hemolytic anemia and/ or thrombocytopenia), however, have a significantly higher serum cytotoxic capacity than do those patients without hematologic involvement. This relationship holds even if the comparison is limited to the $25 \mathrm{pa}$ tients without CNS disease. Thus, although lymphocytotoxic antibodies are present in the sera of a majority of patients with SLE, the cytotoxic capacity is greater in the sera of those patients with CNS involvement and hematologic abnormalities. The increased cytotoxic capacity can not be attributed solely to the severity of the SLE, since it is not found in association with kidney, skin, or serosal involvement.

\section{DISCUSSION}

Absorption with normal brain tissue from the cerebral cortex removes most of the lymphocytotoxic antibodies from SLE sera. In every case studied, brain absorption eliminated greater than $90 \%$ of the cytotoxic capacity. Absorption of three of six SLE sera reduced the cytotoxic capacity to the same level as a similarly absorbed noncytotoxic NHS, indicating that the brain tissue may have removed all of the lymphocytotoxic antibodies from those sera. The other three sera, however, retained residual lymphocytotoxicity that could not be removed with additional brain absorptions. Most lymphocytotoxic antibodies, therefore, are directed at anti- 
genic determinants that are found both on lymphocytes and central nervous tissue. A subset of antilymphocyte antibodies, however, react with antigenic determinants that lymphocytes do not share with the brain.

Cross-reactivity between lymphocytes and brain antigens has been extensively studied in mice. Antibodies directed at the $\theta$-marker, an alloantigen present on $\mathrm{T}$ lymphocytes, cross-react with mouse brain (12). In addition, heterologous antisera produced against mouse brain contain lymphocytotoxic antibodies specific for $\mathrm{T}$ cells (16). The naturally occurring thymocytotoxic antibody that increases with age in NZB mice is relatively $\mathrm{T}$-cell specific, and this, too, cross-reacts with mouse brain antigens (17-19). Thus, there is ample evidence in mice of shared antigenic determinants on $\mathrm{T}$ cells and central nervous tissue.

Lymphocytotoxic antibodies in SLE sera and the naturally occurring thymocytotoxic antibody of NZB mice share several characteristics. Both are $\operatorname{IgM}$ antibodies with increased binding affinity in the cold, and both are directed at antigenic determinants that are found on brain as well as lymphocytes. In mice, brain-reactive lymphocytotoxic antibodies are specific for $\mathrm{T}$ cells, but that is not so in SLE sera. As studies using purified $\mathrm{T}$ - and B-cell populations from normal individuals have shown, lymphocytotoxicity in SLE serum is effective against $B$ and $T$ cells. Furthermore, the nonbrainreactive lymphocytotoxic antibody remaining in the brain-absorbed sera kills both $B$ and $T$ cells equally. The elutable antibodies also are cytotoxic to both $\mathrm{T}$ and $B$ cells. With the warm elution we presumably recovered only those antibodies with heightened binding affinity in the cold. There may be other brain-reactive antibodies, perhaps $T$-cell specific, that we did not recover. If present, however, T-cell-specific antibodies constitute only a small fraction of the total pool of lymphocytotoxic antibodies since we have found that a B-cell lymphoblast cell line maintained in tissue culture removed all of the lymphocytotoxicity. from our sera (unpublished observation). Thus, the lymphocytotoxic antibodies in SLE appear to be directed at antigenic determinants shared by both $\mathrm{B}$ and $\mathrm{T}$ cells.

The cytotoxic antibodies, up to now, have been identified by their antilymphocyte property. They, therefore, are presumed to have been induced by lymphocyte membrane antigens. One current hypothesis suggests that the putative causitive agent of SLE (virus?), when infecting lymphocytes, causes a new antigenic determinant to appear on the cell surface. This neoantigen provides the carrier determinant necessary to overcome self-tolerance and permits cooperation between $T$ cells recognizing this antigen and $B$ cells reactive with antigenic determinants present on normal lymphocytes. The lymphocyte-directed antibodies, thus produced, cross-react with brain constituents. Alterna- tively, the cytotoxic immunoglobulins may originate as antibody to brain. According to this hypothesis, some insult to the CNS causes an alteration of brain antigens which induces autoantibodies directed at nervous tissue. Thus, while truly antibodies to brain, they have depended on their cross-reactivity with lymphocyte membrane antigens for their detection. Since at least $80 \%$ of SLE patients have some cytotoxic antibody, and since clinically apparent CNS involvement occurs in less than half of SLE patients, this hypothesis would require a high incidence of subclinical CNS disease. In this regard, however, among the other disorders associated with appreciable lymphocytotoxic activity, there are several that have CNS disease as a clinical feature. Multiple sclerosis is an obvious example (20), but viral diseases that may produce encephalitis such as rubella, rubeola, and infectious mononucleosis also have lymphocytotoxic antibodies appearing during the acute stages of the disease (21). Furthermore, there is a recent report describing antibodies to mouse thymocytes in the sera of schizophrenic individuals (22).

CNS involvement in SLE has many clinical presentations including psychosis, aseptic meningitis or encephalitis, organic brain syndrome, isolated seizure disorders, and cerebral vascular accidents. While some of the well-localized events can be ascribed to a discrete vasculitis, the pathogenic mechanisms responsible for the more diffuse CNS problems have not been well defined. Immune complex deposition has been demonstrated in the choroid plexus (23). The function of this network of vessels is to sieve the blood for the production of cerebrospinal fluid much like the glomerulus filters the blood for urine production. It has been postulated that deposits in the choroid might alter normal cerebrospinal fluid dynamics, thereby producing some of the CNS manifestations seen in SLE. However, the deposition of immune complexes does not necessarily imply a pathologic role. For example, there are capillaries at the dermal-epidermal junction of the skin which act as a sieve for blood-borne nutrients. In many patients with SLE, immune complexes and complement are found at that location whether or not there are abnormalities in the overlying skin (24).

Circulating brain-reactive antibodies may be responsible for some forms of SLE-CNS disease. Antibodies to lymphocyte membrane constituents can interfere with cell function in vitro (6-9). The mechanism of this suppression has not been elucidated. Antibodies may block access to specific lymphocyte receptors. Alternatively, they may impair membrane dynamics. In guinea pigs, for instance, suppression of immune response genecontrolled antigen stimulation by alloantisera appears to be the result of an alteration of the cell membrane that prevents the lymphocyte from responding to the presence of the antigen in its receptor (25). Antibodies 
attached to neurons may, likewise, produce membrane changes that interfere with the normal propagation of electrical impulses; thereby disturbing CNS function. The development of CNS manifestations, according to this model, requires that brain-reactive antibodies have access to the central nervous tissue. Although most patients with SLE have brain-reactive lymphocytotoxic antibodies in their circulation, the antibodies could reach the CNS only if there was a breakdown in the bloodbrain barrier. Immune complex induced injury could cause the loss of integrity of this barrier.

The cytotoxic capacity is higher in the sera from patients with CNS involvement than it is in the sera of other SLE patients. This difference cannot be attributed solely to greater disease activity in the former group since a similar comparison of those with and without renal disease reveals no significant difference. In fact, of the several manifestations of SLE examined, other than CNS disease, only the presence of a hematologic abnormality (thrombocytopenia or hemolytic anemia) is associated with significantly higher serum lymphocytotoxicity. This latter association may reflect a common mechanism for the induction of autoantibodies against a number of blood constituents. Recent studies in mice have demonstrated that, in addition to antibodies to lymphocytes, heterologous antibrain sera also contain antibodies directed at the stem cell precursors of erythrocytes, platelets, and neutrophils (26). Butler et al. (27) have previously reported that SLE patients with CNS disease and hematologic abnormalities were more like to have circulating lymphocytotoxic antibody than were other SLE patients.

The association of CNS disease with high titer lymphocytotoxic antibody is based on a retrospective analysis of the clinical records of patients whose sera we had previously tested for cytotoxic capacity. Although there was no conscious selection of serum samples, we recognize that this process may have introduced an inapparent bias. In the absence of any obvious bias however, these results should stimulate further investigation into the role of lymphocyte-directed antibody in the development of the CNS manifestations of SLE.

\section{ACKNOWLEDGMENTS}

We thank Kay Dailey for valuable technical assistance and Patty Rasmussen for secretarial assistance in the preparation of this manuscript.

This paper was supported in part by U. S. Public Health Service research grants AM 14916 and AI 10931 from the National Institutes of Health.

\section{REFERENCES}

1. Winchester, R. J., J. B. Winfield, F. Siegal, P. Wernet, Z. Bentwich, and H. G. Kunkel. 1974. Analyses of lymphocytes from patients with rheumatoid arthritis and systemic lupus erythematosus. Occurrence of inter- fering cold-reactive antilymphocyte antibodies. J. Clin. Invest. 54: 1082-1092.

2. Messner, R. P., M. S. Kennedy, and J. G. Jelinek. 1975. Antilymphocyte antibodies in systemic lupus erythematosus. Effect on lymphocytes surface characteristics. $\mathrm{Ar}$ thritis Rheum. 18: 201-206.

3. Terasaki, P. I., V. D. Mottironi, and E. V. Barnett. 1970. Cytotoxins in disease. Autocytotoxins in lupus. $N$. Engl. J. Med. 283 : 724-728.

4. Mittal, K. K., R. D. Rossen, J. T. Sharp, M. D. Lidsky, and W. T. Butler. 1970. Lymphocyte cytotoxic antibodies in systemic lupus erythematosus. Nature (Lond.). 225 : $1255-1256$.

5. Stastny, P., and M. Ziff. 1971. Antibodies against cell membrane constituents in systemic lupus erythematosus and related diseases. I. Cytotoxic effect of serum from patients with systemic lupus erythematosus (SLE) for allogenic and for autologous lymphocytes. Clin. Exp. Immunol. 8: 543-550.

6. Wernet, P., and H. G. Kunkel. 1973. Antibodies to a specific surface antigen of $\mathrm{T}$ cells in human sera inhibiting mixed leukocyte culture reactions. J. Exp. Med. 138 : 1021-1026.

7. Williams, R. C., Jr., R. B. Lies, and R. P. Messner. 1973. Inhibition of mixed leukocyte culture responses by serum and $\gamma$-globulin fractions from certain patients with connective tissue disorders. Arthritis Rheum. 16: $597-605$.

8. Cousar, J. B., and D. A. Horwitz. 1973. Inhibition of lymphocyte activation by sera of patients with systemic lupus erythematosus. Arthritis Rheum. 16: 539. (Abstr.)

9. Conley, M. E., and H. G. Bluestein. 1975. Serum mediated suppression of in vitro lymphocyte function in systemic lupus erythematosus. Clin. Res. 23: 104A. (Abstr.)

10. Lies, R. B., R. P. Messner, and R. C. Williams, Jr. 1973. Relative T-cell specificity of lymphocytotoxins from patients with systemic lupus erythematosus. $A r$ thritis Rheum. 16: 369-375.

11. Winfield, J. B., R. J. Winchester, P. Wernet, S. M. Fu, and H. G. Kunkel. 1975. Nature of cold reactive antibodies to lymphocyte surface determinants in systemic lupus erythematosus. Arthritis Rheum. 18: 1-8.

12. Reif, A. E., and J. M. V. Allen. 1964. The AKR thymic antigen and its distribution in leukemias and nervous tissues. J. Exp. Med. 120: 413-433.

13. Cohen, A., and J. J. Canoso. 1972. Criteria for the classification of systemic lupus erythematosus-status. Arthritis Rheum. 15: 540-543.

14. Boyum, A. 1968. Isolation of mononuclear cells and granulocytes from human blood. Scand. J. Clin. Lab. Invest. 21 (Suppl. 97) : 77-89.

15. Julius, M. H., E. Simpson, and L. A. Herzenberg. 1973. A rapid method for the isolation of functional thymusderived murine lymphocytes. Eur. J. Immunol. 3: 645649.

16. Golub, E. S. 1971. Brain-associated $\theta$-antigen: reactivity of rabbit anti-mouse brain with mouse lymphoid cells. Cell. Immunol. 2: 353-361.

17. Shirai, T., and R. C. Mellors. 1972. Natural cytotoxic autoantibody against thymocytes in NZB mice. Clin. Exp. Immunol. 12: 133-152.

18. Auer, I. O., T. B. Tomasi Jr., and F. Milgram. 1974. Natural thymocytolytic autoantibodies in NZB and other strains of mice. Cell. Immunol. 10: 404-414.

19. Parker, L. M., T. M. Chused, and A. D. Steinberg. 1974. Immunofluorescence studies on thymocytotoxic 
antibody from New Zealand black mice. J. Immunol. 112: 285-292.

20. Van den Noort, S., and R. L. Stjernholm. 1971. Lymphotoxicity in multiple sclerosis serum. Neurology. 21: 783-793.

21. Mottironi, V. D., and P. I. Terasaki. 1970. Lymphocytotoxins in disease. I. Infectious mononucleosis, rubella and measles. In Histocompatibility Testing. P. I. Terasaki, editor. Munksgaard, A/S, Copenhagen. 301308.

22. Luria, E. A., and I. V. Domashneva. 1974. Antibodies to thymocytes in sera of patients with schizophrenia. Proc. Natl. Acad. Sci. U. S. A. 71 : 235-236.

23. Atkins, C. J., J. J. Kondon, Jr., F. P. Quismorio, and G. J. Friou. 1972. The choroid plexus in systemic lupus erythematosus. Ann. Intern. Med. 76: 65-72.
24. Kay, D. M., and D. L. Tuffanelli. 1969. Immunofluorescent techniques in clinical diagnosis of cutaneous disease. Ann. Intern. Med. 71: 753-762.

25. Bluestein, H. G. 1974. Alloantiserum-mediated suppression of histocompatibility-linked $I r$-gene controlled immune responses. Suppressive effects of IgG fragments derived from alloantisera. J. Exp. Med. 140: 481-493.

26. Golub, E. S. 1972. Brain-associated stem cell antigen: an antigen shared by brain and hemopoietic stem cells. J. Exp. Med. 136 : 369-374.

27. Butler, W. T., J. T. Sharp, R. D. Rossen, M. D. Lidsky, K. K. Mittal, and D. A. Gard. 1972. Relationship of the clinical course of systemic lupus erythematosus to the presence of circulating lymphocytotoxic antibodies. Arthritis Rheum. 15: 231-238. 